\title{
INTERTEXTUALIDADE NA LITERATURA: DIÁLOGOS ENTRE MACHADO DE ASSIS E WILLIAM SHAKESPEARE
}

\author{
INTERTEXTUALITY IN LITERATURE: \\ DIALOGUES BETWEEN MACHADO DE ASSIS AND WILLIAM SHAKESPEARE
}

Recebido: 15/04/2021

Aprovado: 21/06/2021

DOI: $10.18817 /$ rlj.v5i01.2577

Publicado: $30 / 07 / 2021$

Rubenil da Silva Oliveira ${ }^{1}$

Orcid ID: https://orcid.org/0000-0001-9846-4695

\begin{abstract}
Resumo: Este artigo visa analisar as ocorrências da intertextualidade nas obras que remetem o leitor às peças shakespearianas. Isto porque obras como "Dom Casmurro" (1899) e o conto "A Cartomante" (1884) levam o leitor machadiano a contemplar "Otelo" e "Hamlet", do autor inglês. Entende-se a intertextualidade como as alusões e citações de textos já escritos em outras épocas, mas que foram utilizados como recurso para a formulação de novos textos, podendo assim ser chamados de intertextos. É também um fator intra-linguístico que pode ser explícito ou implícito, dependendo da escrita e intencionalidade do autor do novo texto, no caso da escrita machadiana, as intertextualidades são evidenciadas logo na primeira leitura. Outro traço é que esse fator de textualidade nas obras do bruxo do Cosme Velho se dá pela semelhança, na qual fica perceptível que ele concorda e, é leitor contumaz do texto shakespeariano e dele se apropria para desenvolver melhor a sua escrita. A escrita machadiana tem como um dos aspectos centrais a intertextualidade, sendo que esta se configura na retomada do tema do envenenamento em "Dom Casmurro", na qual Bentinho pensa em envenenar-se e depois em envenenar o filho Ezequiel e para iniciar essa ação o narrador lembra-se da morte de Desdêmona, em "Otelo". No conto "A Cartomante", o narradorobservador inicia a narração citando "Hamlef", o que alude ao adultério enquanto temática abordada no conto. Para isso, fez-se necessária a leitura das obras de Machado de Assis e dos dramas de Shakespeare, além de leituras sobre a intertextualidade em Koch e Travaglia (1995), Fávero (1991) e Fiorin e Savioli (2007). Portanto, a intertextualidade enquanto fator de textualidade é expressa nas obras de Machado de Assis na retomada das temáticas já apresentadas nas obras de William Shakespeare.
\end{abstract}

Palavras-Chave: Intertextualidade. Tema. Machado de Assis. William Shakespeare.

Abstract: This article aims to analyze the occurrences of intertextuality in the works that refer readers to Shakespearean plays. This is because the reading of works such as "Dom Casmurro" (1899) and "A Cartomante" (1884) by Machado de Assis reminds the reader of "Othello" and "Hamlet" by the English author. Intertextuality is understood as the allusions and quotations from texts already written in other times, but were used as a resource for the formulation of new texts, and that way called "intertextos". It is also an intra-linguistic factor that may be explicit or implicit, depending on the writing and intentionality of the author of the new text. In the case of Machado's writing, intertextuality is evident at the first reading. Another trait is that this factor of textuality in works like "Bruxo do Cosme Velho" is clear by similarities. It is noticeable that he agrees, and is a reader of Shakespearean texts appropriating them to better develop his writing. Machado writings have as one of the central aspects the intertextuality, and this is configured in the resumption of the theme of poisoning in "Dom Casmurro" in which Bentinho thinks about poisoning himself and then poison the son Ezekiel and to initiate this action the narrator remembers the death of Desdemona in "Othello". In the short story "A Cartomante", the narrator-observer begins the narration quoting "Hamlet," which alludes to adultery while thematic of the tale. For this, it was necessary to read the works of Machado de Assis and the

\footnotetext{
${ }^{1}$ Graduado em Letras (UEMA); Mestre em Letras - área de concentração - Literatura, memória e cultura (UESPI); Doutor em Letras - área de concentração: Estudos literários; Professor Adjunto I de Literaturas de Língua Portuguesa (UFMA), coordenação de Letras, Campus Bacabal; Professor permanente do Programa de Pós-graduação em Letras de Bacabal (PPGLB/UFMA). Vice-líder do Grupo de Pesquisa Literatura, enunciação e cultura (LECULT). E-mail: rubenoliveira50@hotmail.com
} 
dramas of Shakespeare, as well as readings on intertextuality in Travaglia and Koch (1995), Fávero (1991) and Fiorin and Savioli (2007). So, while intertextuality of textuality factor is expressed in the works of Machado de Assis in the resumption of the themes already presented in the works of William Shakespeare.

Keywords: Intertextuality. Theme. Machado de Assis. William Shakespeare.

\section{Introdução}

O leitor machadiano frequentemente se depara no texto do Bruxo do Cosme Velho com citações de autores clássicos como Goethe, Stendhal, Sterne, Shakespeare assim como com os textos bíblicos. Nessa perspectiva, a estrutura das narrativas do autor é construída a partir de mitos greco-romanos ou bíblicos, com menções aos clássicos da literatura, o que constitui a presença de forte arraigamento cultural e domínio do fator textual - intertextualidade. O domínio do uso desse fator de textualidade acaba por exigir do leitor de Machado de Assis um amplo repertório cultural, o qual oportuniza a compreensão das relações entre as obras, do contrário, a leitura desse autor é invalidada.

A partir dessa constatação sobre a obra machadiana e da proposição de que há um diálogo frequente entre Machado de Assis e William Shakespeare, convém a problematização - Como Machado de Assis constrói o diálogo com obras de William Shakespeare? Qual a intenção de Machado de Assis ao produzir o fenômeno da intertextualidade na estruturação das narrativas literárias? Essas questões propõem a necessidade da compreensão sobre o que é a intertextualidade e como esse fator intra-linguístico é utilizado pelo autor brasileiro para (re)ssignificar a escrita do autor inglês.

Sabe-se que o termo intertextualidade se deu por proposição de Júlia Kristeva (1979), a qual retoma a ideia de dialogismo proposta em Bakhtin². O conceito de intertextualidade de Kristeva quando aplicado nos texto literários analisados nesse artigo chama a atenção para o fato de que a escrita literária de Shakespeare é atualizada por Machado de Assis. Tomando como base essa constatação, compreende-se que toda obra literária sempre apresenta relações implícitas ou explícitas com obras produzidas em períodos anteriores.

\footnotetext{
2 Ver. BAKHTIN, Mikhail. Estética da criação verbal. Trad. Paulo Bezerra. São Paulo: Martins Fontes, 2003.
} 
Nas produções analisadas, Hamlet, por exemplo, foi publicada, em 1601, e Otelo, em 1603, enquanto A Cartomante foi escrita, em 1884, e Dom Casmurro, em 1899. Desse modo, entende-se que os textos machadianos retomam as produções shakespearianas evidenciando, assim, a intertextualidade. Neste sentido, pode-se afirmar que "[...] todo texto se constrói como mosaico de citações, todo texto é absorção e transformação de um outro texto" (KRISTEVA, 1979, p.68).

Outro conceito de intertextualidade que ressignifica o conceito dado por Kristeva foi formulado por Barthes na obra Inéditos, na qual ele expressa que é no texto que a língua adquire a sua concretude, ou seja, é só por meio da criação de um texto que se dá o caráter concreto à experiência linguística.

O texto redistribui a língua (é o campo dessa redistribuição). Um dos
caminhos dessa desconstrução-reconstrução é permutar textos, retalhos de
textos que existiram ou existem em torno do texto considerado e finalmente
nele: todo texto é um intertexto; outros textos estão presentes nele, em
níveis variáveis, com formas mais ou menos reconhecíveis. [...] A
intertextualidade, condição de todo texto, seja ele qual for, não se reduz,
evidentemente, a um problema de fontes ou influências; o intertexto é um
campo geral de fórmulas anônimas, cuja origem raramente é detectável, de
citações inconscientes ou automáticas, dadas sem aspas. (BARTHES,
2004, p. 275).

Considerando que 0 presente artigo tem por objetivo a análise das ocorrências da intertextualidade de Shakespeare em Machado de Assis, é possível verificar o modo como o autor brasileiro se apropria de modo explícito de parte das peças dramáticas do autor inglês. Devido a essa constatação, compreende-se que no texto literário, a intertextualidade consiste na atividade de reconstituição dos significados do primeiro texto, inovando-o, com o intuito de retomar a temática ou de parodiá-lo. No caso específico das obras analisadas, Machado de Assis adota-as na perspectiva do mesmo campo semântico, sendo que as citações de Shakespeare apenas agem como reforçadores do argumento machadiano.

As intertextualidades no campo da escritura literária deram margem a outras leituras e pesquisas na área de Letras, inclusive na Linguística Textual, na qual se percebe importantes contribuições de Ingedore G. Villaça Koch, Leonor Lopes Fávero, dentre outros. Contudo, a exploração das intertextualidades de Shakespeare em Machado de Assis ainda é pouco vista no cenário das produções científicas brasileiras, sobretudo, no Maranhão e Piauí.

Convém ressaltar que o "Bruxo do Cosme Velho" não é o único que se vale do discurso intertextual na literatura brasileira, há muitos outros, uma vez que usar 
desse recurso é uma manifestação já comum nos textos literários. Por outro lado, ele desde a sua produção poética mostra-se um leitor voraz dos dramas shakespearianos, como destacado no fragmento que segue:

\begin{abstract}
Shakespeare foi um dos autores mais citados por Machado de Assis. Em mais de cinquenta anos de carreira, o autor brasileiro se referiu ao bardo inglês e/ou a seu trabalho mais de 300 vezes em cerca de 170 textos, considerando os vários gêneros em que compôs (TELES, 2012, p. 1).
\end{abstract}

Porém, como não há espaço para a análise de toda a produção machadiana, este artigo trata apenas de duas peças do autor inglês intertextualizadas pelo autor brasileiro - "Otelo" e "Hamlet", respectivamente, nas obras "Dom Casmurro" e " $A$ Cartomante".

\title{
2 Intertextualidade: a ressignificação do texto literário
}

Os estudos sobre a intertextualidade na literatura não representam nenhuma inovação, pois desde os anos de 1970, há a preocupação com a investigação desse campo na pesquisa científica. Porém, há alguns motivos que tornam necessária essa investigação a partir da leitura dos textos machadianos e shakespearianos: 1 . O lugar de destaque ocupado pela intertextualidade na literatura, linguística e nas ciências humanas; 2. A necessidade de compreensão das intertextualidades para dar sentido à obra literária e; 3. Para aprofundamento dos motivos expressos anteriormente procurar entender como Machado de Assis nos situa na renovação da linguagem shakespeariana de modo a inovar a linguagem e métodos de construção da escrita literária.

Nessa perspectiva, o leitor é guiado a lembrar-se de que a intertextualidade se faz necessária para a compreensão dos elementos situados na superfície do texto, assim não se pode dizer que o sujeito entendeu Machado de Assis sem visitar a obra de Shakespeare. Isto porque não se trata apenas de um recurso estético, mas de um elemento crucial na construção do horizonte de expectativas do leitor, ou seja, para se apropriar do que fato diz Shakespeare e assim conferir que novo significado é atribuído a ele pelo enigmático autor brasileiro. Nesse caso, ressalta-se que a intertextualidade pode ter por intento construir ou desconstruir significados já dados à obra literária e se a intencionalidade do autor que faz uso desse recurso é 
afirmar o sentido dado pelo autor primeiro ou simplesmente parodiá-lo. Por isso, ressalta-se que,

Conforme Beaugrande e Dressler, a intertextualidade compreende as diversas maneiras pelas quais a produção e recepção de dado texto depende do conhecimento de outros textos por parte dos interlocutores, isto é, diz respeito aos fatores que tornam a utilização de um texto dependente de um ou mais textos previamente existentes. (KOCH \& TRAVAGLIA, 1995, p. 88).

Em conformidade com o excerto acima, a não leitura do texto shakespeariano inviabiliza o entendimento da escritura machadiana, uma vez que o intertexto age como elemento mediador da construção de sentidos do texto. A essa ideia acrescenta-se o fato de que "[...] nossa memória textual atua no tecido de nossos discursos, ligando os contextos históricos e impregnando de sentido os textos que produzimos". (AZEREDO, 2007, p.133). Nesse sentido, afirma-se que é na capacidade de armazenamento das informações constitutivas da memória que o sujeito linguístico é capaz de dar sentido ao novo texto. Por outro lado, a intertextualidade possibilita a construção da coerência textual como admitido pelos autores citados, uma vez que ela é marca singularizada na produção verbal humana.

A compreensão do fenômeno intertextual depende das leituras acumuladas na experiência dos leitores, isto se deve ao fato de que há obras que somente podem ser reveladas se o leitor tiver conhecimento de outras já existentes. Por essa razão, o leitor é orientado a pensar da individualidade e da coletividade no ato da criação literária, uma vez que "todo texto é produto de criação coletiva: a voz do seu produtor se manifesta ao lado de um coro de outras vozes que já trataram do mesmo tema e com as quais se põe em acordo ou desacordo". (FIORIN \& SAVIOLI, 2007, p.90). De acordo com os autores o uso da intertextualidade tem por objetivo aprovar ou discordar do texto já construído, além de admitir o processo de inovação como dependente da criação do autor, uma vez que o tema do adultério, por exemplo, foi já trabalhado nas obras de Shakespeare no século XVII e, no século XIX, retomado por Machado de Assis nas suas criações da estética realista.

Admite-se que a prática da intertextualidade e os fatores de coerência textual funcionam como agentes potencializadores da construção de sentido, pois é através deles que é tornado possível imbricar-se na apreensão das estruturas textuais. Por outro lado, é da possibilidade de entendimento dessas estruturas que o leitor reconhece os diálogos existentes entre os textos, inclusive os que remetem à 
presença da intertextualidade, ativando o reconhecimento das estruturas macrotextuais e micro-textuais. (FÁVERO, 2002).

As produções literárias contemporâneas exprimem de modo usual a retomada de conceitos e temas das estéticas já consolidadas no cânone da literatura, o que as faz adquirir o status de "grande rede intertextual", que repercute o fluxo dinâmico das relações da atualidade.

As produções humanas, embora aparentemente desconexas, encontram-se em constante inter-relação. Na verdade, constrói-se uma grande rede, com o trabalho de indivíduos e grupos, onde os fios são formados pelos bens culturais. Se se considerar toda e qualquer produção humana como texto a ser lido, reconstruído por nós, a sociedade pode ser vista como uma grande rede intertextual, em constante movimento. O espaço da cultura é, pois, intertextual (WALTY; PAULINO; CURY, 1995, p.12).

Tomando como base o excerto acima, afirma-se que a utilização da intertextualidade mesmo manifestada na cultura contemporânea e, por conseguinte, na produção literária dessa época ela não é exclusiva desse período. Como já expresso, esse recurso está imbricado no texto literário desde o período clássico, nessa dimensão, o texto machadiano acaba por subverter as obras de Shakespeare e possibilita ao leitor a leitura de uma nova obra que toma por pressuposto uma ideia e obra já existente, mas que tem sua autonomia.

\subsection{Otelo versus Dom Casmurro: diálogos intertextuais}

O diálogo que Machado de Assis desenvolve em "Dom Casmurro" com o drama "Otelo", de William Shakespeare toma como referência o ciúme que Bentinho nutre da esposa Capitu nos capítulos sessenta e dois, cento trinta e cinco e cento trinta e seis, respectivamente, nominados de "Uma ponta de lago" "Otelo" e "A xícara de café". A situação dialógica entre as obras tem como vínculo o ciúme que as personagens masculinas Bentinho e Otelo têm das esposas Capitu e Desdêmona, respectivamente, é nesse jogo acusatório de infidelidade que acontece a aproximação das personagens femininas.

Os casais do "Bruxo do Cosme Velho" e os do autor inglês têm sua vida conjugal devassada pela suspeita do adultério, sendo que na obra machadiana a suspeita é inicialmente levantada por José Dias, o agregado da família de Bentinho e mais tarde sustentada pela voz do narrador. Para isso, ele procura através de conjecturas traçar um perfil negativo da esposa para culpá-la, julgando-a 
dissimulada, enganosa e calculista, além de cogitar no envenenamento do filho do casal, de quem ele suspeita que seja a prova material do adultério. Já na obra de Shakespeare quem implanta a dúvida da traição na cabeça de Otelo é lago, o alferes de Otelo.

No capítulo "Uma ponta de lago" o grande mentiroso é José Dias, o qual poderia ser chamado de lago à brasileira, que na tentativa de acabar com a relação afetiva de Bentinho e Capitu implanta em Bentinho a dúvida sobre a fidelidade do sentimento de Capitu. José Dias não é nenhum pouco inocente, ele sabia que ao responder a pergunta de Bentinho, que estava no Seminário por imposição da promessa feita por D. Glória, antes mesmo de ele nascer, causaria no jovem o ciúme. A pergunta feita a José Dias é - “Capitu como vai?” (ASSIS, 2010, p. 105). E ele responde: "- Tem andado alegre, como sempre; é uma tontinha. Aquilo, enquanto não pegar algum peralta da vizinhança que case com ela...". (ASSIS, 2010, p. 105).

Diante da resposta de José Dias, Bentinho deixa o leitor notar que o seu estado de espírito muda, pois ele empalidece, sente frio, esperava ele uma resposta contrária, uma vez que confessa que chorava todas as noites. Mesmo ele reconhecendo que suas ações eram hiperbólicas, deixa-se corroer pela ideia do ciúme, como visto no trecho seguinte:

Outra ideia, não - um sentimento cruel e desconhecido, o puro ciúme, leitor das minhas entranhas. Tal foi o que me mordeu, ao repetir comigo as palavras de José Dias: "Algum peralta da vizinhança". Em verdade, nunca pensara em tal desastre. Vivia tão nela, dela e para ela, que a intervenção de um peralta era como uma noção sem realidade; nunca me acudiu que havia peraltas na vizinhança, vária idade e feitio, grandes passeadores das tardes. Agora me lembrava de que alguns olhavam para Capitu - e tão senhor que me sentia dela que era como se olhassem para mim, um simples dever de admiração e de inveja. Separados um do outro pelo espaço e pelo destino, o mal me aparecia agora, não só possível, mas certo. E a alegria de Capitu confirmava a suspeita; se ela vivia alegre é porque já namorava a outro, acompanhá-lo-ia com os olhos na rua, falarIhe-ia à janela, às ave-marias, trocariam flores e... (ASSIS, 2010, p. 106).

Considerando a resposta de José Dias e a angústia monológica de Bentinho, nota-se que o agregado é colocado pelo autor em posição análoga à do alferes lago na conversa que este mantém com Otelo no drama de Shakespeare. Salvo a diferença de que em Otelo há o diálogo construído de modo velado e estratégico por lago para que ele não fosse julgado pelo amigo, tampouco causasse algum comprometimento na amizade dos dois, enquanto em Machado de Assis há apenas 
a pergunta feita por Bentinho ao José Dias e a resposta deste que causa o ciúme do jovem. Vejamos o diálogo entre Otelo e lago:

OTELO - Minha deliciosa coitadinha! Que a perdição tome conta de minha alma, mas eu te amo! E quando não mais te amar, o caos se estabelecerá uma vez mais.

IAGO - Meu nobre senhor...

OTELO - O que dizes, lago?

IAGO - Miguel Cássio, quando o senhor cortejava esta que agora é sua esposa, ele sabia de seu amor por ela?

OTELO - Sabia, desde o primeiro instante. Por que perguntas?

IAGO - Para a mera satisfação da curiosidade de meus pensamentos. Não é por mal.

OTELO - Por que essa curiosidade de teus pensamentos, lago?

IAGO - É que pensei que ele não a conhecesse de antes.

OTELO - Ah, sim, e serviu-nos de mensageiro seguidas vezes.

IAGO - Não diga!

OTELO - Não digo? Digo sim. Não discernes coisa alguma nisso? Não é ele honesto?

IAGO - Honesto, meu general?

OTELO - Honesto! Sim, honesto.

IAGO - Meu general, por tudo que sei.

OTELO - O que estás pensando?

IAGO - Pensando, meu general?

OTELO - "Pensando, meu general"! Pombas, agora és meu eco, como se houvesse algum monstro em teu pensamento, hediondo demais para mostrar-se. Tencionas dizer algo. Escutei-te dizer agora mesmo não gostaste do que viste, quando Cássio despediu-se de minha esposa. Pois não gostaste do quê? $E$ quando te falei que foi meu conselheiro durante todo o tempo em que cortejei Desdêmona, gritaste "Não diga!" e enrugaste a testa e fechaste o cenho, como se tivesses encarcerado em teu cérebro algum terrível conceito. Se por mim tens afeição, revela-me teus pensamentos. (SHAKESPEARE, 2009, p. 83-84).

Evidencia-se que a resposta de José Dias e a conversa de lago servem como semeaduras da discórdia, cada qual com o seu objetivo e dentro das armaduras psicológicas criadas por seus autores. Ambos agem para suscitar nos seus senhores (protagonistas) a corrosão pelo ciúme doentio, sentimento esse que contribui para a transformação das relações amorosas e encaminha-os ao desfecho de suas vidas, o herói de Shakespeare suicida-se, já o de Machado de Assis, entrega-se a sua casmurrice.

Outro diálogo com a obra de Shakespeare proposto por Machado de Assis é encontrado no capítulo intitulado "Otelo", ou seja, um homônimo perfeito da obra shakespeariana, aqui fica perceptível uma referência intertextual explícita do autor brasileiro ao autor inglês. A ação do capítulo dá-se quando Bentinho pensa acerca das aproximações e distanciamentos da sua trajetória e da do nobre mouro a serviço do Estado de Veneza. 
Jantei fora. De noite fui ao teatro. Representava-se justamente Otelo, que eu não vira nem lera nunca; sabia apenas o assunto, e estimei a coincidência. Vi as grandes raivas do mouro, por causa de um lenço - um simples lenço! -, e aqui dou matéria à meditação dos psicólogos deste e de outros continentes, pois não me pude furtar à observação de que um lenço bastou a acender os ciúmes de Otelo e compor a mais sublime tragédia deste mundo. [...] O último ato mostrou-me que não eu, mas Capitu devia morrer. [...]

- E era inocente - vinha eu dizendo rua abaixo. - Que faria o público, se ela deveras fosse culpada, tão culpada como Capitu? E que morte Ihe daria o mouro? Um travesseiro não bastaria; era preciso sangue e fogo, um fogo intenso e vasto, que a consumisse de todo, e a reduzisse a pó, e o pó seria lançado ao vento, como eterna extinção... (ASSIS, 2010, p. 187).

$\mathrm{Na}$ volta para casa, Bentinho tece conjecturas sobre a inocência de Desdêmona e a culpa que ele põe em Capitu, inclusive pensa em que tipo de morte seria mais adequada para que sua mulher não deixasse qualquer vestígio. Em "Otelo", para livrar-se da suspeita de adultério da esposa, o mouro de Veneza manda que o alferes lago mate a Cássio, o tenente de quem lago levantara a suspeita de que fosse amante de Desdêmona e resolve matar a esposa no próprio leito, onde ele considera que tenha acontecido a traição.

OTELO - Bem, faze isso, e sê breve. Enquanto isso, eu dou uma caminhada. Eu não mataria o teu espírito despreparado. Não... Deus me livre! ... Eu não mataria a tua alma.

DESDÊMONA - Falas em matar?

OTELO - Sim, falo em matar.

DESDÊMONA - Pois então que os céus tenham piedade de mim!

OTELO - Amém, é o que desejo com todo o meu coração.

DESDÊMONA - Se falas assim, espero que não me mates.

OTELO - Hmm!

DESDÊMONA - E, no entanto, tu me assustas, pois sabes ser fatal quando reviras os olhos dessa maneira. Por que deveria eu assustar-me contigo não faço a menor ideia, uma vez que desconheço culpas. Todavia, me sinto assustada.

OTELO - Pensa em teus pecados.

DESDÊMONA - Todos eles são amores que entrego em ti, para ti. OTELO - Sim, e por isso tu morres.

$[\ldots]$

DESDÊMONA - Ah, podes me mandar para o exílio, meu senhor, mas não me mates.

OTELO - Não te levantes, rameira!

DESDÊMONA - Mata-me amanhã, deixa-me viver esta noite!

OTELO - Não, se tu lutares...

DESDÊMONA - Ao menos meia hora!

OTELO - Depois de começado não há como parar.

DESDÊMONA - Ao menos enquanto eu faço uma prece!

OTELO - É tarde demais. (SHAKESPEARE, 2009, p. 158-161).

Enquanto Desdêmona é morta, mesmo sendo inocente, a também inocente Capitu carrega as marcas da desconfiança do marido psicótico que no capítulo " $A$ xícara de café", lembra-se da morta do drama inglês "comecei a mexer o café, os 
olhos vagos, a memória em Desdêmona inocente; o espetáculo da véspera vinha intrometer-se na realidade da manhã" (ASSIS, 2010, p.188). Depois de despejar o veneno na xícara de café, café esse que ele pensa em beber, mas quando viu o filho, pensa em dar-lhe o café.

No desfecho da narrativa machadiana a visão de que Capitu é adúltera projetada na mente de Bentinho não é desfeita, enquanto na peça de Shakespeare apesar da morte física de Desdêmona o leitor ou espectador sabe da inocência dela. Assim, em Shakespeare há o arrependimento de Otelo por saber que lago tinha mentido e devido a isso do alferes ter matado a amada, recorrendo ao suicídio. Por outro lado, o narrador machadiano continua querendo tornar o leitor cúmplice dos devaneios de que fora traído pela mulher e pelo amigo: "[...] uma coisa fica, [...] a minha primeira amiga e o meu maior amigo, tão extremosos ambos e tão queridos também, quis o destino que acabassem juntando-se e enganando-me... A terra lhes seja leve!". (ASSIS, 2010, p. 200).

2.2 Hamlet versus A Cartomante: citação, um recurso intertextual

Na narração do conto "A Cartomante", escrito em 1884, Machado de Assis desde as primeiras linhas intenciona demonstrar a partir da ótica filosófica e psicológica o desencantamento com a vida, o mundo e as pessoas. Para isso, usa dos pressupostos cientificistas da época e do pessimismo que the é peculiar, recorrendo ainda à leitura de Hamlet, de William Shakespeare, quando Camilo faz zombarias, devido ao fato de Rita contar-Ihe que tinha ido à casa de uma cartomante à procura de entender os mistérios da vida.

HAMLET OBSERVA A HORÁCIO que há mais coisas no céu e na terra do que sonha a nossa filosofia. Era a mesma explicação que dava a bela Rita ao moço Camilo, numa sexta-feira de novembro de 1869, quando este ria dela, por ter ido na véspera consultar uma cartomante; a diferença é que o fazia por outras palavras. (ASSIS, 2013, p. 15).

Observa-se que a citação do clássico de Shakespeare reflete a necessidade de maior repertório cultural do leitor para associar o excerto machadiano à cena $\mathrm{V}$ do Ato I do drama:

HAMLET - Disseste bem velha toupeira! Como trabalhas depressa debaixo da terra! Valente gastador! Mais uma vez, meus bons amigos, mudemos de lugar. 
HORÁCIO - Oh! Pelo dia e pela noite! É um prodígio estranho!

HAMLET - Por consequência acolhei-o, como se faz a um estranho. Horácio, no céu e na terra há mais coisas do que sonha a vossa filosofia. Mas vamos: agora aqui jurai, como há pouco fizestes, que nunca - assim Deus vos ajude! -, por mais extravagante e insólito que seja o meu procedimento (porque talvez se me afigure necessário afetar de hoje em diante um caráter fantástico), jurai que a ver-me assim, nunca denotareis saber de mim alguma coisa, cruzando os braços deste feitio, ou abanando com a cabeça, ou pronunciando alguma frase duvidosa como: "Bem, bem, nós sabemos"; ou: "Nós podíamos se quiséssemos"; ou: "Se tivéssemos vontade de falar"; ou: "Há gente que, se pudesse..." ou quaisquer palavras igualmente ambíguas. Jurai isso, e a graça e favor do céu vos assista nas vossas aflições! Jurai. (SHAKESPEARE, 2010, p. 46-47).

Ao aproximar os dois textos, percebeu-se que o "Bruxo do Cosme Velho" se apropria de parte da última fala de Hamlet procurando a partir de um novo contexto dar maior amplitude e sentido aos mistérios que o homem mesmo no contexto cientificista da segunda metade do século XIX desconhecia. Seguindo esse raciocínio, o leitor de Machado de Assis é conduzido a perceber o quão contraditória são as relações humanas, como as apresentadas no conto, no qual a amizade é corroída pelo adultério entre Rita, que era mulher do Vilela e Camilo. Nesse jogo das relações humanas, somam-se os mistérios de cada personagem, ingenuidade, malícia, sinceridade e hipocrisia, o que cede lugar à reflexão acerca da mesquinhez e precariedade do homem.

Ainda no conto "A Cartomante", o autor cita a obra de Shakespeare ao dizer que: "Foi então que ela, sem saber que traduzia Hamlet em vulgar, disse-lhe que havia muita coisa misteriosa e verdadeira neste mundo. Se ele não acreditava, paciência, mas o certo é que a cartomante adivinhara tudo". (ASSIS, 2010, p.15-16). Compreende-se que esse excerto serve para dinamizar as ações da narrativa e aumentar o horizonte de expectativas do leitor, mantendo este preso ao desenvolvimento da narração, sem esse recurso a narrativa passaria quase que imperceptível e o epílogo não faria sentido algum.

Sem a presença da intertextualidade da obra shakespeariana "há mais coisas no céu do que sonha a nossa vã filosofia", que funciona como anticlímax do conto, o autor procura preparar o espírito do leitor para o desfecho da narração. Assim sendo, é pela força desse recurso que Machado de Assis conduz o enredo em torno do seu próprio eixo, os mistérios da vida, que podem levar os amigos a corromperem suas relações de amizade em nome do amor e dos mistérios que nem a filosofia desvendou, no entanto, o desfecho é, por sua vez, irônico e, se não tivesse esse tom não seria a escrita machadiana. 


\section{Conclusão}

Entende-se a intertextualidade como recurso linguístico-literário do qual os escritores apropriam-se para construir seus textos como meio de ressignificar ou refutar os textos já produzidos em outras épocas, nos casos analisados, os textos shakespearianos são produções do início do século XVII e os machadianos das últimas décadas do século XIX. Entretanto, a intertextualidade do texto shakespeariano feita por Machado de Assis tem por objetivo reafirmar ou dá atualidade ao texto primeiro, o que não altera a originalidade ou o espírito criacionista do autor.

Ao aproximar as obras "Otelo", de William Shakespeare e "Dom Casmurro", de Machado de Assis, verificou-se que há na obra do escritor brasileiro três referências intertextuais explícitas da peça teatral "Otelo" do autor inglês. Também em "Dom Casmurro" é citada a peça "Mulheres patuscas de Windsor", escrita em 1602, de Shakespeare. A intertextualidade em Machado de Assis se dá na perspectiva da alusão e estilização da obra para se referir ao tema da suposição caluniosa do adultério e com isso demonstrar a morte física de Desdêmona e a morte social de Capitu, uma vez que ela é condenada ao exílio na Europa pelo narrador. O distanciamento das duas ocorre no desfecho trágico dado por Shakespeare a sua obra, enquanto Machado de Assis usa da ironia para fazer o leitor apiedar-se do espírito de Bento Santiago, na sua casmurrice buscando sustentar que a esposa e o melhor amigo tinham-no traído.

O contato com a leitura de Hamlet é exigido do leitor machadiano desde o epílogo do conto, devido à importância e o modo como o autor estrutura a narrativa de "A Cartomante" presa à citação do autor inglês, uma vez citação intertextual é o fio condutor da tessitura da história. Portanto, as intertextualidades de Shakespeare em Machado de Assis atualizam a obra e conferem novos significados para a mesma.

\section{Referências Bibliográficas}

ASSIS, Machado de. A Cartomante. In.: Várias Histórias. 3. ed. São Paulo: Martin Claret, 2013. 
. Dom Casmurro. 9. ed. São Paulo: Martin Claret, 2010. (Coleção a obra prima de cada autor; 1 ).

AZEREDO, José Carlos de. Ensino de português: fundamentos, percursos, objetos. Rio de Janeiro: Jorge Zahar, 2007.

BAKHTIN, Mikhail. Estética da criação verbal. Trad. Paulo Bezerra. São Paulo: Martins Fontes, 2003.

BARTHES, Roland. Inéditos. São Paulo: Martins, 2004.

FÁVERO, Leonor Lopes. Coesão e coerência textuais. São Paulo: Ática, 2002.

FIORIN, José Luiz, SAVIOLI, Francisco Platão. Para entender o texto: leitura e redação. 17. ed. São Paulo: Ática, 2007.

KOCH, Ingedore Grünfeld Villaça. TRAVAGLIA, Luiz Carlos. Texto e coerência. 4. ed. São Paulo: Cortez, 1995.

KRISTEVA, Julia. Introdução à semanálise. São Paulo: Perspectiva, 1979.

SHAKESPEARE, William. Hamlet. Trad. José Antonio de Freitas. São Paulo: Martin Claret, 2010. (Coleção a obra prima de cada autor; 39).

Otelo. Trad. Beatriz Viégas-Faria. 1. reimpr. Porto Alegre: L\&PM, 2009. (Coleção L\&PM POCKET; 174).

TELES, Adriana da Costa. Shakespeare na obra de Machado de Assis: números e reflexões. In.: III CONGRESSO INTERNACIONAL DA ABRAPUI. Language and Literaturein in the Age of Technology. Florianopólis: Universidade Federal de Santa Catarina, 2012. (Comunicação oral).

TRAVAGLIA, Luiz Carlos. Gramática e interação: uma proposta para o ensino de gramática. 7. ed. São Paulo: Cortez, 1995.

WALTY, I.; PAULINO, G.; CURY, M. Z. F. Intertextualidades: teoria e prática. 2. ed. Belo Horizonte: Lê, 1995. 